\title{
Barriers to Physician Aid in Dying for People with Disabilities
}

\author{
Alicia Ouellette \\ Albany Law School, Albany, NY 12208, USA; aouel@albanylaw.edu \\ Received: 5 September 2017; Accepted: 19 October 2017; Published: 1 November 2017
}

\begin{abstract}
Terminally ill people with disabilities face multiple barriers when seeking physician aid in dying (PAD) in the United States. The first is legality. Efforts to legalize the practice have been thwarted in dozens of states in part due to vocal opposition by advocates for people with disabilities who contend that legalized aid in dying discriminates against and harms people with disabilities by leading to their premature and unnecessary deaths. Some disability rights advocates disagree with their colleagues, however, and support legalization on the ground that it promotes autonomy and independence at the end of life. For proponents, legalization in six states is proving to be an illusive victory. Emerging reports from the states where PAD is legal suggest that people with disabilities may face special and impenetrable barriers when seeking legal aid in dying. This article identifies four such barriers: procedural protections embedded in PAD statutes; physician objection; cost; and a rule pertaining to California veterans. The article calls for additional study to determine the extent to which these barriers have a disparate impact on care options available to terminally-ill people with disabilities.
\end{abstract}

Keywords: disability; physician aid in dying; death with dignity; access; disparate impact

\section{Introduction}

Terminally ill people with disabilities face multiple barriers when seeking physician aid in dying (PAD) in the United States. PAD is the practice by which physicians provide competent, terminally ill patients prescriptions for medications the patients can self-administer to achieve death. For some disability rights advocates, this is a good thing. Important organizational and individual disability rights advocates maintain that PAD demeans and imperils the lives of individuals living with disabilities (Sutton 2017; Gorman 2015). For other advocates, however, access to PAD is critical to empowering individuals with autonomy and independence at the end of life by allowing patients to control the timing and circumstances of their deaths (Batavia 2003). For proponents of PAD, statutes in California, ${ }^{1}$ Colorado, ${ }^{2}$ the District of Columbia, ${ }^{3}$ Oregon, ${ }^{4}$ Vermont,${ }^{5}$ and Washington, ${ }^{6}$ and a court decision in Montana ${ }^{7}$ providing legal mechanisms to facilitate individual choice at the end of life constitute empowering victories. Patients in those states have a legal means to work with their physicians to control the circumstances of their deaths through aid in dying. As is true with much in healthcare, however, what is available in theory is sometimes illusory in practice, especially for people

\footnotetext{
California End of Life Option Act, Cal. Health \& Safety Code $\S \S 443-443.22$ (West) (2016).

Colorado End of Life Options Act, Colo .Rev. Stat. Ann. § 25-48-101-25-48-123 (West) (2016).

District of Columbia Death with Dignity Act of 2016, D.C. Law 21-182 (West) (2017).

Oregon Death with Dignity Act, OR. REV. STAT. § 127.80 (2016).

Vermont Patient Choice at the End of Life Act, VT. Stat. Ann. tit 1-5293 (West) (2013).

The Washington Death with Dignity Act, Wash. Rev. Code Ann. §70.245 (West) (2009).

Baxter v. Montana, 224 P.3d 1211 (Montana Sup. Ct. 2009).
} 
with disabilities. When it comes to accessing PAD, procedural, practical, and attitudinal barriers affect people with disabilities, even in states where PAD is legal.

This article explores barriers to PAD for those persons with disabilities seeking it. The most significant barrier, of course, is legality. Disability rights groups have taken a lead role preventing legalization of PAD through effective litigation and legislative advocacy. Introducing arguments made by disability advocacy groups in opposition to PAD, which are written about in more depth elsewhere (Asch 2001; Gill 1996), the article contrasts those arguments with contrary positions taken by disability rights advocates who support access to PAD. The purpose of this discussion is not to debate the merits of either point of view, but to explain why some disability advocates position themselves against others who support access to PAD, creating an effective barrier to access to those seeking PAD in most states. Following that discussion, the paper examines emerging evidence that, even where PAD is legal, procedural and practical realities impede access for persons with disabilities.

In particular, the article explores four barriers to access beyond legality: procedural safeguards included in PAD statutes, a lack of willing providers, increasing drug costs, and special issues faced by California veterans. In the context of a national debate about whether legalized aid in dying will harm people with disabilities by leading to their premature and unnecessary deaths, the available data and reports from states that have made PAD a legal medical option suggest that concerns about overuse or abuse are unrealized. To the contrary, people with disabilities may in fact face special and impenetrable barriers when seeking legal aid in dying. Because data has not been collected on denials of and barriers to access to PAD, further study is needed to determine the extent to which those barriers have a disparate impact on care options available to terminally-ill people with disabilities.

\section{The Resistance-Why Some Disability Advocates Oppose PAD}

Major disability rights groups are among the fiercest advocates against laws that would allow PAD. Not Dead Yet, Adapt, the Association of Programs for Rural Independent Living, Autistic Self Advocacy Network, the Center for Disability Rights, the National Council on Independent Living, and others take strong and effective positions against the practice in court cases, demonstrations, and lobbying efforts (Disability Rights Amici 2016). Their basic position is that PAD, which opponents characterize as legally assisted suicide, discriminates against and threatens the lives of all people with disabilities.

For example, a coalition of national, state, and local disability rights groups submitted an amicus brief in a pending New York State case arguing that PAD can only be understood in the context of the "United States' long and tragic history of state-sanctioned discrimination against disabled people" (Disability Rights Amici 2016). Pointing to examples such as institutionalization, state-sponsored sterilization, and the withholding of lifesaving medical assistance from disabled newborns by medical professionals, the coalition argues that medical providers cannot be trusted to value disabled lives when individuals with disabilities seek aid in dying (Disability Rights Amici 2016). Throughout history, the advocates maintain, medical professionals have taken the view that "[p]ermanent disability ... is the problem, [and] death is the solution" (Advocacy Center for Persons with Disabilities, Inc. 1997). The advocates point out that physician predictions of life quality and expectancy can be and often are wrong, undervaluing the possibility of quality life for individuals living with disabilities. Therefore, they maintain, "[i]t is extremely dangerous to respond to the expression of a death wish by providing the means to die. That type of response, especially if it comes from a respected authority ... (e.g., a physician), can unduly influence a vulnerable individual to embrace death as the 'right' solution," leading "to the wrongful premature deaths of persons who, if given basic support and reasonable options instead of a socially and medically sanctioned exit, would prefer to live"(Disability Rights Amici 2016).

In this context, advocates argue, the first right of people with disabilities is "a claim to life itself" (Asch 2001). Assisted suicide denies people with disabilities, including those with and without terminal conditions, the benefit of the state's suicide prevention laws. "Remove the disability", they suggest, 
"and the support for a person's right to kill themselves, or for a doctor to kill the person, disappears. This is the prejudice that pervades our society" (Advocacy Center for Persons with Disabilities, Inc. 1997). In this way, they contend, assisted suicide will not be a choice "[u]ntil society is rid of the prejudice that devalues a life with a disability ... Rather, it will be a rational decision that reflects the bigotry of persons who see a life with a disability as a tragic life that would be better off not existing" (Advocacy Center for Persons with Disabilities, Inc. 1997).

Opponents also argue that PAD is inherently coercive in the absence of a right to healthcare:

"[w]ithout a concomitant constitutional right to receive medical treatment such as palliative care and hospice services without regard to ability to pay, there is no sufficient constitutional safeguard to ensure that the decision to seek a physician's assistance to die will be the result of free choice, not dictated by insurance coverage decisions and other economic pressures. Without a right to treatment services for clinical depression or other causes of a suicidal crisis, people who might overcome their despair with supports may instead choose premature death." (Disability Rights Montana 2009)

Thus, the advocates argue, limiting assisted suicide to "voluntary requests" fails to protect people with disabilities from potential abuse and premature death. The arguments are effective; advocates have effectively thwarted efforts to legalize PAD in dozens of states, thereby creating barriers to access even for members of the disability community who support it.

\section{Autonomy Matters-Disability Advocates for PAD}

Focusing on the principles of autonomy and independence that have long been cornerstones of the disability rights movement, a handful of disability rights advocates, the proponents, actively support choice at the end of life, including PAD. For example, a disability rights group argued in an amicus brief submitted to the New Mexico Supreme Court in favor of PAD, "how a person faces their own death is a private and intimate. The decision that should be made by that person and a personal alone. Nobody else, particularly the state should have the power to take away that most private and intimate decision" (ALS Association New Mexico Chapter 2015). Views to the contrary are viewed as unfortunately paternalistic, undermining the right of individuals with disabilities "to make choices and maintain control in all aspects of their lives" (Autonomy, Inc. and Cascade Aids Project 2005). Challenges to legalized PAD on the ground that the practice "poses a threat to individuals who are ill and vulnerable ... erroneously assumes that members of these groups are not capable of making a rational and voluntary decision" (Autonomy, Inc. and Cascade Aids Project 2005).

Proponents reject the argument that state laws allowing physician assisted death will have the cumulative impact of devaluing the lives of people with disabilities on the ground that "[q]uality of life is a subjective valuation that belongs to the individual, not to anyone else" and "[b]y permitting that individual 'to make [a] judgment about the quality of life that [he or she] may enjoy,' PAD 'gives proper recognition to the individual's interest in choosing a final chapter that accords with [his or] her life story, rather than one that demeans [his or] her values and poisons memories of [that person]"” (Autonomy, Inc. and Cascade Aids Project 2005).

In this way, proponents view the effective advocacy by opponents from the disability advocacy community as blocking access to choices they wish to have, thereby limiting full expression of their own life narrative. Opponents erect barriers to PAD to ensure that disabled lives are not unfairly or mistaking devalued. In so doing, they limit choices for those who in fact find their lives lack quality, insisting that all lives are of high enough quality to continue regardless of the suffering that can accompany terminal illness.

In spite of strong opposition from much of the disability advocacy community, proponents have succeeded legalizing PAD in six states and the District of Columbia. 


\section{Fears Unrealized: No Evidence of Overuse or Coercion}

Where legalized by statute, PAD is strictly regulated and monitored. The laws require that two doctors agree that the patient has an incurable illness that will lead to death within six months, that the patient make multiple requests for the lethal prescription, that the patient has the mental capacity to make decision, and that the patient self-administer the legal dose. The laws also require extensive reporting. The most robust data sets are from Oregon, where PAD was legalized in 1998 (Oregon Health Authority 2016), and Washington, which began implementation in 2008 (Washington State Department of Health 2017). California implemented its End of Life Option Act on 9 June 2016, and began collecting data immediately (California Department of Public Health 2016). The data provide insight into how PAD is actually being used, and a basis for research. Researchers who have analyzed the data have found no evidence that fears of abuse of or overuse of PAD against people with disabilities expressed by opponents are being realized (Blanke et al. 2017; Battin 2008; Su 2013; Battin et al. 2007).

The data from all three states show more than a third of the people who go through the multistep process to receive PAD choose not to use the prescription after receiving it. In 19 years of legalization in Oregon, for example, a total of 1749 prescriptions were written, and 1127 patients (64.5\%) died by using the legally prescribed lethal medication (Oregon Health Authority 2016). The data from California show that in its first year (from 9 June to 31 December 2017), 191 people were granted prescriptions to end their lives, and that of those 191, 111 (58\%) ingested the lethal medication (California Department of Public Health 2016).

As to demographics, the data show that most patients who use PAD have some form of cancer, and are overwhelmingly white, college educated, and in hospice care. Of the 1127 Oregon patients who ingested the lethal medication, $872(77.4 \%)$ had cancer, $89(8 \%)$ had amyotrophic lateral sclerosis, $46(4.1 \%)$ had lung disease, 35 (3.1\%) had heart disease, and $10(0.9)$ had HIV. Of the 1127, 96.6\% were white and $90.5 \%$ in hospice care. $95 \%$ had a high school education and $72.8 \%$ had attended college (Oregon Health Authority 2016). The demographics are similar in California (California Department of Public Health 2016) and Washington (Washington State Department of Health 2017).

From these data, and in the absence of verified reports of coercion or exploitation of people with disabilities or other vulnerable groups, analysis has concluded that there is simply no evidence of coercion of people with disabilities or other vulnerable groups, despite predictions to the contrary (Tucker 2017). To the extent that the experience from states where PAD is legal illuminates disability-based disparities, the concern is not overuse, but a lack of access for people with disabilities. For example, a report on testimony by the executive director of protection and advocacy organization Disability Rights Oregon suggests that the only disability discrimination occurring with the act is the exclusion of people with disabilities from PAD:

DRO has not received a complaint of exploitation or coercion of an individual with disabilities in the use of Oregon's Death with Dignity Act. Complaints have focused on the concern that the Dignity Act might discriminate against persons with disabilities who would seek to make use of the Act that have disabilities which would prevent self-administration, thereby denying these persons the ability to use the Dignity Act. (Tucker 2017)

The following section identifies some of the reasons people with disabilities may be having difficulty accessing PAD.

\section{Practically Speaking—Legalizing PAD Does Not Guarantee Access for Persons with Disabilities}

While several states collect data about the use of physician aid in dying, none collects data about unsuccessful attempts to access PAD. Media and other reports help fill in the blanks (Hosseini 2017c; Bharaha 2017). At least four barriers appear to impede access to PAD in states where it is legal. These barriers include procedural protections designed to prevent abuse of PAD, the reluctance of physicians to participate, rising drug costs, and a California regulation directed at veterans. 
In the absence of data, it is impossible to know how many individuals have been denied or faced impenetrable barriers accessing PAD, or how many affected individuals are or were living with disabilities. The available California data suggest that the percentage of people denied access could be as high as $25 \%$ of those seeking PAD: in the first six months of California's End of Life Option Act, 258 people formally started the process by making two verbal requests to their physicians at least 15 days apart, but only 191 received prescriptions-meaning 67 people were denied or lost interest in PAD (California Department of Public Health 2016). However, because the state does not track initial requests, denials, or delays in provision of care, and the state does not ask those who made a first request only why they did not follow through, it is not known how many qualified people were unable to access PAD, or the circumstances that prevented access. If collected, such data would shed light on whether and to what extent people with disabilities seeking PAD are affected by barriers. To be sure, there is some risk that collecting data from those who choose against PAD after making a first request could appear coercive. Care would need to be taken in designing methods to collect such data to mitigate the risk of even subtle messaging for or against completion of the PAD process.

\subsection{Procedural Protections Intended to Protect Vulnerable Populations from Abuse}

In response to concerns that PAD could be misused against vulnerable populations, state statutes limit its availability with a series of procedural safeguards. The Oregon statute is the model. Oregon's Death with Dignity Act established tightly controlled procedures under which a competent, terminally ill adult may obtain a prescription for medication that he or she can self-ingest to bring about a peaceful death. For the patient to be eligible, the attending physician must determine that the patient is an Oregon resident, is mentally competent, and confirm the patient's diagnosis and prognosis. Only those with a terminal disease that is "an incurable and irreversible disease that has been medically confirmed and will, within reasonable medical judgment, produce death within six months" qualify. The Act requires a 15-day waiting period between the patient's initial oral request and the writing of the prescription, and a 48 hour waiting period between the patient's written request and the writing of the prescription. ${ }^{8}$ The attending physician must inform the patient of his or her diagnosis and prognosis, the risks and probable results of taking the medication, and alternative to aid in dying, including palliative and hospice care. A second consulting physician must confirm the attending physicians' medical opinion. Once a request from a qualifying patient has been properly documents and witnessed, the attending physician may prescribe the lethal medication. The physician cannot administer the medication-the patient must self-ingest. Similar restrictions apply in California, Washington, Vermont, the District of Columbia, and Colorado.

For some patients seeking PAD, these protections become impenetrable barriers to care (Hughes 2015). Because the law legal competence, wide swaths of people with intellectual disabilities are never eligible. Patients with progressive diseases like Alzheimer's and ALS are denied access because they lose competence before they are within six months of death, or because physicians are unable to certify when the illness will be terminal as defined by law (Henig 2015).

The requirement of self-administration poses particular problems for Huntington's sufferers. Huntington's disease is a progressive, neurodegenerative disorder that is inevitably fatal. Marked by involuntary movements, swallowing disorders, the inability to speak, and cognitive impairments, Huntington's patients may lose the ability to self-ingest prescription medicine before they are eligible for PAD, by being deemed within six months of death, or by completing the multistep process of approvals. The self-ingestion requirement becomes an impenetrable barrier for those seeking PAD, leading families of individuals with Huntington's to argue in court briefs that the so-called protective procedures discriminate based on disability status (NYS Court of Appeals 2017). 
The 15-day waiting period also proves to be a barrier to access to PAD for those whose condition is rapidly deteriorating. For example, a report from California indicates that at least one the patient became lost the competence between the time she made her first, valid request for PAD, and her second (Hosseini 2017b). She was unable to access PAD despite repeated and consistent intention to do so. The 15-day waiting period becomes even more burdensome in areas in which physicians are unavailable or unwilling to participate.

\subsection{A Lack of Willing Providers}

The barriers to PAD created by the 15-day waiting period are exacerbated by a lack of willing trained providers. The lack of providers is particularly acute in California, where there are reports of "death-with-dignity blackout[s]" (Hosseini 2017a). Throughout California, major hospital systems have decided against participating in the End of Life Options Act. The nonparticipating systems include hundreds of secular and Catholic-affiliated providers. The blackouts have created problems for communities such as Rancho Mirage, with concentrated senior populations, and a single controlling health system. "'Not only do they have the hospital, but they have 65 clinics in that area they operate.' ... By monopolizing health care, [a single system] has 'effectively cut off access to a whole region of people'" (Hosseini 2017a).

In other cases, some patients claim that recalcitrant physicians actively hindered their ability to exercise their rights under California's End of Life Option law. The family of Judy Dale is suing the UC San Francisco Medical Center on this ground, alleging that her physician and the system misrepresented that they would provide aid in dying when her terminal cancer had advanced to the point where she was ready to die (Seipel 2017). The suit claims that despite Dale's repeated and clear indications to doctors and social workers that she intended to exercise her option to use a lethal prescription when pain became unbearable, the providers made a "conscious choice to suppress and conceal their decision" against participating in the law until it was too late for her to make different plans.

The problem of recalcitrant providers is not unique to California. In Vermont, a group of providers sued to avoid participating in the process, eventually entering a Consent Agreement and Stipulation with the Vermont attorney general providing that medical providers "do not have a legal professional obligation to counsel and refer patients for the Patient Choice at End of Life process" unless a patient requests such information. (State of Vermont, Office of the Attorney General 2017).

\subsection{Increasing Drug Costs}

Cost presents another barrier to PAD care. The cost of barbiturates prescribed to terminally ill patients, such as the preferred drug Seconal, soared after California proposed legislation to legalize aid in dying. The standard lethal dose, which involves emptying 100 capsules of Seconal into a beverage, cost just $\$ 150$ five years ago; it now costs $\$ 3000$ or more (Offord 2017). While the cost may be covered by Medicaid and some private insurers, it is not covered by Medicare, the main coverage for many users. To provide alternative cheaper options, physicians and patients are turning to compounded drug substitutes, which neither tested or proven as effective as Seconal (Offord 2017).

\subsection{Special Issues for Veterans}

A regulation promulgated by the California Department of Veterans Affairs (CalVet) following the passage of California's End of Life Option Act presents a special problem for veterans seeking to access PAD. Cal. Code Regs. tit. 12, §509 ("section 509") mandates eviction of residents of State homes intending to consume medication prescribed pursuant to the End of Life Option Act. CalVet explained that it adopted $\S 509$ because of a perceived conflict between California and federal law. See 42 U.S.C. § 14402. In issuing this regulation, CalVet assumed that the federal statute prohibits any aid-in-dying services or drugs from being provided in any State home. It thus put California Veterans, many of who live with disabilities, in the position of facing eviction should they pursue PAD. 
The conclusion by CalVet that federal law prohibits the aid-in-dying services from being performed at State homes is questionable. 42 U.S.C. § 14402(a)-(c) prohibits the use of federal funds for aid-in-dying services, but does not prohibit not what services may or may not take place at State homes. CalVet is concerned, however, that it would jeopardize its federal funding were it to permit residents to use aid-in-dying on its premises. It has thus decided to evict terminally ill residents who seek aid-in-dying.

Given the number of veterans who live with disabilities, it is likely that section 509's threat of eviction for those individuals seeking PAD will disproportionally affect persons with disabilities. Further study is needed to determine the full impact of the regulation.

\section{A Call for Further Study}

Procedural safeguards, unwilling providers, drug cost, and the veteran-specific regulation affect access to PAD for people with and without disabilities. Further study is needed to determine the extent of their impact on people with disabilities, but there is no question these barriers affect people with disabilities seeking PAD. Individuals with intellectual disabilities are never eligible, and individuals with conditions that are progressively debilitating become ineligible. Where physicians and healthcare systems opt out of participating in PAD, people living with disabilities may be disproportionately affected if they do not have the means to escape PAD blackout areas and find a willing provider. Drug costs are a concern for people with disabilities who, on average, earn less money than able-bodied counterparts. With 3.8 million veterans living with service related disabilities, the CalVet regulation is likely to have a significant impact on disabled veterans (United States Census Bureau 2015). Moreover, terminal illness often brings with it disabling conditions rendering many of those persons seeking PAD disabled.

Further study is needed to quantify the effects of barriers to PAD on persons with disabilities. Such study is warranted. Some number of terminally ill people with disabilities live in states where PAD is a legally and medically viable option. As a matter of equity and good policy, it is important to understand the extent to which people with disabilities are able to access legal, available methods of care, including all components of palliative, hospice, and end of life options. Early reports suggest that legalized aid in dying may in fact be an unobtainable option, even where proponents have achieved legality. Further study is appropriate.

Conflicts of Interest: The author declares no conflict of interest.

\section{References and Notes}

Advocacy Center for Persons with Disabilities, Inc. 1997. Initial brief, Krischer v. McIver (1997 WL 33491585).

ALS Association New Mexico Chapter. 2015. Amicus Curiae Brief in Support of Plaintiffs-Petitioners at 5, Morris v. Bradgenberg, 356 P. 3d 546 (N.M. Ct. App 2015) (No. 33, 630).

Asch, Adrienne. 2001. Disability, Bioethics, and Human Rights. In Handbook of Disability Studies. Edited by Gary L. Albrecht, Katherine D. Seelman and Michael Bury. Thousand Oaks: Sage Publications, pp. 297-301.

Autonomy, Inc., and Cascade Aids Project. 2005. Amicus Brief in Support of Plaintiffs, Gonzales v. State of Oregon (2005 WL 1715164).

Batavia, Andrew I. 2003. Disability Rights in the Third Stage of the Independent Living Movement: Disability Community Consensus, Dissention, and the Future of Disability Policy. Stanford Law E Policy Review 14: 347-50.

Battin, Margaret P. 2008. Physician Assisted Dying and the Slippery Slope: The Challenge of Empirical Evidence. Willamette Law Review 45: 91-99.

Battin, Margaret P., Agnes van der Heide, Linda Ganzini, Gerrit van der Wal, and Bregje D Onwuteaka-Philipsen. 2007. Legal Physician Assisted Dying in Oregon and the Netherlands: Evidence Concerning the Impact on Patients in "Vulnerable" Group. Journal of Medical Ethics 33: 591-97. [CrossRef] [PubMed] 
Bharaha, Deepa. 2017. A Year after it Passed, California's Right-to Die Law Still Faces Challenges. The Orange County Register. Available online: http:/ / www.ocregister.com/2017/06/07/right-to-die-law-one-yearlater-challenges-remain/ (accessed on 30 October 2017).

Blanke, Charles, Michael LeBlanc, Dawn Hershman, Lee Ellis, and Frank Meyskens. 2017. Characterizing 18 Years of the Death with Dignity Act in Oregon. JAMA Oncology 3: 1403-6. [CrossRef] [PubMed]

California Department of Public Health. 2016. California End of Life Option Act 2016 Data Report. Available online: https: / www.cdph.ca.gov / Programs/CHSI/CDPH\%20Document\%20Library/CDPH\%20End\% 20of\%20Life\%20Option\%20Act\%20Report.pdf (accessed on 30 October 2017).

Disability Rights Amici. 2016. Amicus brief submitted for Plaintiffs, Myers v. Schneiderman. New York Court of Appeals, Index No. 151162, 2016 WL 9241003.

Disability Rights Montana. 2009. Amicus Brief, Baxter v. State (2009 WL 1389051).

Gill, Carol J. 1996. Suicide Intervention for Persons with Disabilities: A Lesson in Inequality. Issues in Law $\mathcal{E}$ Medicine 8: 37-53.

Gorman, Anna. 2015. Why Disability-Rights Activists are Fighting Doctor-Assisted Suicide. The Atlantic. Available online: https:/ / www.theatlantic.com/health/archive/2015/06/disability-rights-assisted-suicidecalifornia/397235/ (accessed on 30 October 2017).

Henig, Robin. 2015. Despite Sweeping Aid-in Dying Law, Few Will Have that Option. National Public Radio. Available online: http:/ / www.npr.org/sections /health-shots/2015/10/07/446631786/despite-sweepingdeath-with-dignity-law-few-will-have-that-option (accessed on 30 October 2017).

Hosseini, Raheem F. 2017a. Desperate to Die. News Review. Available online: https:/ /www.newsreview.com/ chico / desperate-to-die/ content?oid=24550322 (accessed on 30 October 2017).

Hosseini, Raheem F. 2017b. Killing Mom: A terminal cancer patient wants to die. Will California's end-of-life bureaucracy let her? Sacramento News \& Review. Available online: https://www.newsreview.com/ sacramento/killing-mom-a-terminal-cancer / content?oid=24452593 (accessed on 30 October 2017).

Hosseini, Raheem F. 2017c. The Uncounted Dead: California Doesn't Want to Know Who's Falling through the Crack of its Assisted-Death Law. Sacramento News \& Review. Available online: https:/ / www.newsreview. com/sacramento/uncounted-dead-california-doesnt/content?oid=24602803 (accessed on 30 October 2017).

Hughes, Clair. 2015. New York's physician-assisted suicide bill excludes some patients, death with dignity advocates claim. Albany Times Union, August 1.

NYS Court of Appeals. 2017. Brief Amici Curiae in Support of the Plaintiffs-Appellants, Myers v. Schneiderman. NYS Court of Appeals, Index No. 151162/15.

Offord, Catherine. 2017. Accessing Drugs for Medical Aid-in-Dying. The Scientist. Available online: http:/ / www.thescientist.com/?articles.view/articleNo/49879/title/Accessing-Drugs-for-Medical-Aid-in-Dying/ (accessed on 30 October 2017).

Oregon Health Authority. 2016. Oregon Death with Dignity Act, Data Summary 2016. Available online: http:/ / www.oregon.gov/oha/PH/PROVIDERPARTNERRESOURCES/EVALUATIONRESEARCH/ DEATHWITHDIGNITYACT/Documents/year19.pdf (accessed on 30 October 2017).

Seipel, Tracy. 2017. UCFF sued for refusing to help woman die. The Mercury News. Available online: http:/ / www.mercurynews.com/2017/07/17/family-sues-ucsf-for-agreeing-then-refusing-to-helpwoman-die/ (accessed on 30 October 2017).

State of Vermont, Office of the Attorney General. 2017. Consent Decree, Vermont Alliance for Ethical Healthcare et al. v. Hose, No 5:16-cv-205 (D.Vt.). Available online: https:/ / www.compassionandchoices.org/wp-content/ uploads/2017/08/Exhibit-A-AGO-Letter.pdf (accessed on 21 July 2017).

Su, Anne Marie. 2013. Physician Assisted Suicide: Debunking the Myths Surrounding the Elderly, Poor, and Disabled. Hastings Race and Poverty Law Journal 10: 145-57.

Sutton, Carol Cleigh. 2017. I Oppose Assisted Suicide and Euthanasia because it is Ableist. Not Dead Yet. Available online: http:/ / notdeadyet.org/2017/08/carol-cleigh-sutton-i-oppose-assisted-suicide-and-euthanasiabecause-it-is-ableist.html (accessed on 30 October 2017).

Tucker, Kathryn L. 2017. Building Bridges between the Civil Rights Movements of People with Disabilities and Those with Terminal Illness. University of Pittsburgh Law Review 78: 329-38 (citing Declaration of Robert Joondeph, Executive Director Oregon Advocacy Center, Joondeph Aff., October 2007). [CrossRef] 
United States Census Bureau. 2015. Service-Connected Disability Rating Status and Ratings for Civilian Veterans 18 Years and Over. Available online: https://factfinder.census.gov/fagces/tableservices/jsf/ pages/productview.xhtml?src=bkmk (accessed on 30 October 2017).

Washington State Department of Health. 2017. 2016 Death with Dignity Act Report. Available online: https: / / www.doh.wa.gov / Portals/1/Documents/Pubs /422-109-DeathWithDignityAct2016.PDF (accessed on 30 October 2017). article distributed under the terms and conditions of the Creative Commons Attribution (CC BY) license (http:/ / creativecommons.org/licenses/by/4.0/). 